\title{
LA MISERICORDIA Y LA VOCACIÓN EN LA BIBLIA
}

DOI: https://doi.org/10.52039/seminarios.v62i218.104

«He visto la aflicción de mi pueblo en Egipto, he oído su clamor... Voy a bajar para librarlo...Ve, pues. Yo te envío al faraón para que saques de Egipto a mi pueblo, a los israelitas» (Ex 3, 7.8.10). Estas son las palabras que Dios dirige a Moisés desde la zarza ardiente. Así comienza una misión de salvación para con Israel que llevará al pueblo a la alianza y a la tierra prometida. La vocación de Moisés brota de la mirada misericordiosa de Dios que ve la opresión del pueblo y responde enviando un liberador. Ser llamados por Dios quiere decir entrar en un camino de misericordia haciéndose mediadores de esa misericordia.

Para desarrollar esta idea articularé mi exposición en tres puntos, evocando figuras bíblicas de llamados particularmente significativas, en especial para el camino sacerdotal. Por eso recorreremos primero los acontecimientos fundamentales de la aventura vocacional de Moisés, el gran mediador del amor salvífico de Dios para con Israel, que interviene en el momento fundacional de la historia de la salvación. Pasaremos después a una figura de profeta, Jonás, que pone de relieve la dificultad de responder al llamamiento divino y de aceptar su misericordia, con una vocación que le pide ir más allá de su pueblo para extender las fronteras de la salvación hasta los paganos e incluso al perdón de los enemigos. Por último, abordaremos el cumplimiento neotestamentario con la definitiva manifestación de la misericordia divina en la llamada de los Doce, paradigma de toda vocación a ser discípulos del Señor Jesús y modelo privilegiado de referencia para la misión del sacerdote en el mundo.

\section{Ver la MISERICORDIA DEL SEÑoR}

En la narración de la llamada a Moisés y de su misión, la dimensión de la misericordia reviste un papel fundamental. Todo nace de la misericordia de Dios que ve el sufrimiento de su pueblo y se conmueve tiernamente, no permaneciendo indiferente ante el grito del oprimido, y decidiendo intervenir

* Bruna Costacurta es profesora de Teología bíblica en la Pontificia Universidad Gregoriana de Roma. 
y asumir el cuidado de sus elegidos. Comienza así la historia de Moisés, que es enviado de nuevo a Egipto, de donde había huido aterrorizado después de haberse arrogado la defensa de un hermano hebreo contra un egipcio que lo maltrataba. Ahora, en cambio, obedeciendo a la llamada divina, debe volver al país de su juventud y afrontar el poder del faraón como mediador de la voluntad de salvación de Dios (Ex 3).

El enfrentamiento con el poder egipcio es duro, sin evitar gestos violentos como las diez plagas que culminan con la muerte de los primogénitos, con el mar Rojo que engulle al ejército egipcio. Pero incluso en estos casos, la misericordia es la que misteriosamente guía la historia, porque esos muertos son vistos como parte de un proyecto de amor, porque deberían servir para abrir el corazón de los egipcios ${ }^{1}$, para hacerles entender que al oponerse a Dios, estaban autodestruyéndose y eligiendo la muerte, y que no hay vida posible más que en el reconocimiento de que sólo Dios es el Señor de la vida².

Quien acoge la llamada divina se pone al servicio de esta salvación, que no es el simple «buenísimo» que actúa como si el mal no existiera o finge no verlo; al contrario, lo afronta con toda su seriedad, consciente de que el perdón y la salvación exigen que el pecador reconozca el mal que ha hecho y se convierta confiando en una misericordia mayor que su pecado.

Moisés se hace mediador de esta salvación, primero conduciendo al pueblo fuera de Egipto y después guiándolo a lo largo de todo el camino del éxodo hasta la Tierra prometida.

Durante su peregrinación por el desierto, Israel ha tenido que enfrentarse continuamente con la tentación de la desconfianza, del rechazo, de la rebelión. El desierto, con su vacío y su ausencia de todo, ha sido escuela comprometedora de fe, ha obligado al pueblo a confrontarse con su propia necesidad de Dios mientras que, murmurando y protestando, buscaba una respuesta a las necesidades primarias como el agua y la comida. Los varios episodios de «murmuración» que jalonan la narración del éxodo, ilustran admirablemente una constante de la vida de fe cuando la necesidad de cosas, aunque sean imprescindibles, se absolutiza, se convierte en tentación, lleva a la idolatría. Así sucedió a Israel en Mará ante el agua no potable (Ex 15, 22-26), o en Masá y Meribá (Ex 17, 1-8; Nm 20,1-13), donde ante una sed insoportable el pueblo llega a hacerse la terrible pregunta: «¿Está el Señor en medio de nosotros o no?» (Ex 17,7). Y está también el hambre (Ex 16), y la náusea del maná (Nm 11, 4-8; 21, 4-5), y el pánico de entrar en una tierra donde los habitantes parecían peligrosos ( $\mathrm{Nm} \mathrm{11,} \mathrm{4-8;} \mathrm{21,} \mathrm{4-5).} \mathrm{Y} \mathrm{cada} \mathrm{vez} \mathrm{Dios} \mathrm{responde:} \mathrm{hace} \mathrm{brotar}$

1. Los israelitas verán a los egipcios muertos en la orilla del mar $(E x 14,30)$ y verán la mano poderosa del Señor (Ex 14, 31), pero para ello tendrán que abrirse a la fe y creer.

2. En particular, Ex 14, 4: «Yo haré que el faraón se obstine y os persiga; me cubriré de gloria a costa del faraón y de todo su ejército, y sabrán los egipcios que yo soy el Señor». 
el agua de la roca, manda desde el cielo el maná y codornices al campamento, hace sentir su presencia de Padre misericordioso y providente.

Ya en el mar Rojo el Señor había respondido a la crisis de fe del pueblo que protestaba (Ex 14). Los israelitas, encerrados por el mar y el desierto, con el ejército egipcio persiguiéndolos, habían gritado de pánico y habían acusado a Moisés de haberlos llevado a morir en el desierto cuando habrían podido seguir viviendo seguros en Egipto. Mejor esclavos pero vivos, que libres pero abocados a la muerte. Israel había olvidado ya la intervención gloriosa de Dios que había doblegado la resistencia del faraón y había abierto las puertas de Egipto para que el pueblo pudiera salir «con la cabeza bien alta» (literalmente, «a mano alzada», Ex 14, 8; Nm 33, 3), como triunfador, llevándose el oro y la plata de los egipcios. El mar insalvable, el desierto inmenso y Egipto con sus carros y caballeros acosándolos es el escenario que aparece ante los ojos aterrorizados del pueblo, que acusa a Moisés ${ }^{3}$ y, en él, a Dios mismo. Pero Dios responde a través de su mediador y los llama a la fe, restableciendo la verdad: Él mismo combatirá por su pueblo y lo salvará. El mar se abrirá y dejará pasar a Israel por un camino seco, y Moisés será el intérprete del designio de liberación del Señor indicando al pueblo el camino inimaginable de la compasión divina. Esta es la tarea ligada al compartir la fe, este es el mandato que el sacerdote recibe al ponerse al servicio del proyecto misericordioso de Dios.

Y cuando Israel, siempre olvidadizo de las maravillas obradas por el Señor, siga protestando, Dios, por medio de Moisés, seguirá mostrando su rostro paciente, capaz de un amor sobreabundante: el maná de cada día, las codornices hasta la hartura, el agua para toda la comunidad y para el ganado.

Y además, como don aún mayor, el perdón. Porque llega un momento en que el peso de la vida de fe se hace más agudo y prevalece la tentación de la idolatría. Cuando en el Sinaí desaparece Moisés en la montaña, Israel pide a Aarón que les haga un dios más concreto, tangible, fácilmente perceptible: un becerro de oro que lo represente y muestre visiblemente su presencia (Ex 32; Dt 9). Es la continua tentación del hombre, el poder relacionarse con un dios más comprensible, que haga menos exigente la fe; un dios cuyos pensamientos no difieran demasiado de los nuestros; en definitiva, un dios que, encerrado en una imagen, aunque sea sólo mental, se convierte en un ídolo.

Así, mientras Moisés está en la montaña para recibir las tablas de la Ley y estipular la alianza, Israel se libera de la relación con la divinidad. Y el Señor envía a su mediador a confrontar al pueblo con su propio pecado para que comprenda toda su gravedad, y tomando conciencia de ella, se deje convertir y perdonar. Las tablas de la Ley son destruidas mediante un gesto con el que se expresa la gravedad absoluta de lo que ha sucedido; la alianza se ha

3. Cf., en sentido contrario, Is 55, 8-9. 
terminado antes aun de haberse estipulado, pero la grandeza de la misericordia divina consigue rehacer incluso lo irreparable. Y Moisés, obediente a su vocación, apela a esta misericordia intercediendo por el pueblo, y después destruyendo el becerro, el signo del pecado. La misericordia ha vencido.

Las nuevas tablas que Dios re-escribe en la montaña lo testifican: son las tablas de la gratuidad del amor. Si las primeras podrían crear la ilusión de que el hombre entraba una relación con Dios basada en la propia capacidad y fidelidad, ahora las segundas tablas, signo de un pecado perdonado, testimonian que la alianza del Señor con el hombre se funda sólo en la misericordia divina y en la fidelidad de su amor, anticipación de aquella alianza definitiva que el Hijo de Dios consumará en su sangre.

De esta forma Moisés devuelve de nuevo el pueblo a Dios cumpliendo así su misión. Y al final de su camino dejará al pueblo entrando en la tierra prometida, pero quedando él en el monte Nebo, muriendo allí y haciendo que se perdieran sus huellas (Dt 34). Nadie sabe dónde está su tumba, el mediador de la salvación desaparece una vez que ha terminado su tarea, en una donación total de sí mismo por la que se ha dejado consumir completamente.

Pues bien, en el sacerdote responder a la vocación quiere decir, como en el caso de Moisés, entregarse en ese camino de gracia que nace de la misericordia; quiere decir ver la misericordia del Señor para hacérsela ver al mundo, quiere decir hacerse siervo, y siervo inútil (Lc 17, 7-10), dispuesto incluso a desaparecer para que aparezca sólo la grandeza del amor del Señor.

Un camino que sin duda será arduo, porque muchas veces la misericordia asusta. Es el caso de otro llamado que aparece en la Escritura, el profeta Jonás, cuya historia constituye una meditación para enfrentar los miedos y las dificultades que una vocación divina puede suscitar.

\section{LA DIFICULTAD DE ENTRAR EN EL PROYECTO DE MISERICORDIA DE DIOS}

El profeta Jonás recibe de Dios una misión precisa: ir a Nínive a proclamar el anuncio profético. Nínive, la capital de los asirios, los enemigos por antonomasia de Israel, estaba situada a orillas del río Tigris, en Mesopotamia. Cuando el libro de Jonás se escribe, hacía mucho tiempo que había sido destruida y estaba desierta, pero en la narración es presentada como una gran metrópoli, como lo había sido en sus tiempos de esplendor, símbolo de la riqueza y del máximo y extraordinario poder, aquel poder sanguinario que había destruido y esclavizado el reino del Norte y amenazado también el reino del Sur. Pues es precisamente a esa ciudad a la que es enviado un profeta de Israel, miembro de un pueblo que había sido víctima del imperio asirio.

Una vocación problemática con la que Dios quiere responder al mal de Nínive, pero que Jonás rechaza: Dios manda que se levante y vaya a Nínive, y él se levanta, sí, pero huye en sentido opuesto. Pues Nínive está al este de Israel, 
mientras que Jonás se dirige a Tarsis, un lejano puerto del Mediterráneo, en el extremo oeste. No se indica aquí la razón de la huida (el profeta la explicitará sólo al final de la narración), pero resulta claro que se trata de esquivar una tarea considerada inaceptable, un rechazo radical que no deja lugar a dudas. Así, mientras que Dios declara que el mal de la ciudad «ha subido» hasta él, Jonás «baja» lejos de Dios, hasta Jaffa, y después, en el barco, lejos de la presencia de Dios que le encarga una misión percibida como intolerable.

Durante el viaje por mar se desencadena una tempestad, y Jonás continúa su «bajada»: primero a la bodega de la nave, después al letargo profundo del sueño, intentando olvidar, en una huida de la realidad de la que el sueño es con frecuencia signo ${ }^{4}$.

Ante la furia de la tempestad, los marineros, atemorizados, comienzan a rezar dirigiéndose a sus dioses, la única reacción sensata que se puede adoptar ante la muerte; mientras, el capitán despierta a Jonás rogándole que rece él también. Con ironía humorística y amarga, el narrador presenta a un profeta de Israel que se ve obligado a escuchar a un pagano que le pide que implore ayuda a su Dios, él, que estaba huyendo lejos del Señor.

Después, cuando los marineros echan las suertes y por ellas reciben la confirmación de que Jonás es el responsable de lo que está sucediendo, el profeta les manda que lo arrojen al mar. Él se proclama a sí mismo «temeroso» de Dios, expresión en la que seguramente el «temor» entraña también algo de miedo (en hebreo se usa la misma expresión) y reconoce la propia responsabilidad, sacrificándose para salvarlos, aceptando ser echado al mar y perecer para que los otros puedan salvarse. $Y$ en efecto, la tempestad se calma; y los marineros se convierten y se abren a la fe en el verdadero Dios. Jonás ha sido para ellos verdadero profeta, aunque a su pesar, cumpliendo su tarea de ayuda a la conversión y de entrega de sí mismo. A pesar de todo, Jonás no puede sustraerse a su propia vocación.

Como es sabido, en el mar, por voluntad divina, Jonás es engullido por un pez, desde cuyo vientre eleva su oración, y más tarde es arrojado a la orilla.

Todo comienza de nuevo. Por segunda vez Dios lo llama y lo envía a Nínive. Esta vez Jonás obedece, entra en la ciudad y transmite el anuncio que Dios le ha confiado: «Dentro de cuarenta días Nínive será destruida» (Jon 3, 4). Pero se trata de una obediencia puramente material, sin verdadera adhesión interior al proyecto divino. Jonás ejecuta la orden, pero sin obediencia a la misericordia. Adhiere a la amenaza de la destrucción, pero sin aceptar el sentido de la misma amenaza, que se orienta a convertir y, por lo tanto, a perdonar. Porque lo que la Escritura enseña es que los profetas son enviados por Dios para apelar a la conciencia de los pecadores y llevarlos a la conversión, ayu-

4. Por ejemplo, Elías en el desierto (cf. 1 Re 19, 3-5), o el sueño de los discípulos en el huerto de Getsemaní, donde Lucas indica que se durmieron a causa de la tristeza (Lc 22, 45). 
dándolos a hacerse conscientes de su necesidad de ser perdonados. El envío de Jonás tiene esta finalidad y Jonás es consciente de ello y lo dirá dirigiéndose a Dios cuando ve que los ninivitas se arrepienten: «Por algo me apresuré a huir a Tarsis. Porque sé que eres un Dios clemente, compasivo, paciente y misericordioso, que se arrepiente del mal» $(\text { Jon } 4,2)^{5}$. El grito profético «dentro de cuarenta días Nínive será destruida» no es, por tanto, más que el anuncio de cuarenta días de gracia. Nínive tiene cuarenta días para convertirse y no ser destruida. Jonás lo sabe -y también para nosotros, los lectores, es claro ahora- que ese es el motivo de que Dios envíe al profeta.

Pero Jonás no quiere que Nínive sea perdonada, y cuando los ninivitas hacen penitencia, el profeta, cuya palabra, aunque muy a pesar suyo, ha sido eficaz, se retira airado. Dios perdona a la gran ciudad, y a Jonás esto le parece mal. No le indigna el mal de Nínive, sino que ese mal termine; y su cólera no es como la ira de Dios, que expresa lo insoportable del mal, sino la cólera vindicativa que indica lo insoportable de la bondad de Dios y su perdón ${ }^{6}$. Hasta el punto de querer morir. El rechazo por parte de Jonás de su propia vocación profética se radicaliza y llega hasta el extremo. La misericordia de Dios le ha resultado inaceptable, sobre todo porque se refiere a los enemigos y parece ser contraria a toda justicia.

Ahora la fractura se hace incurable. Jonás se aleja de la ciudad, se coloca a distancia, una actitud que contradice todavía más su propia vocación, rechazando la solidaridad, repudiando aquella conversión que, como profeta, debería haber sido su más íntimo deseo ${ }^{7}$.

Pero Dios es misericordioso e interviene para llevar al profeta Jonás a una nueva toma de conciencia. Hace crecer un ricino para que le dé sombra, después hace que se seque, el sol ardiente cae implacable sobre el profeta acrecentando su deseo de morir. Nínive la sanguinaria está salvada y en cambio el ricino salvador e inocente ha sido destruido sin motivo. Todo parece insensato e inaceptable.

En este punto, Dios pone a Jonás ante el verdadero problema para ayudarle a entender y tener sentimientos de misericordia. Si él puede sentir lás-

5. Cf. Joel 2, 13; también Ex 34, 6; Sal 86, 15; 103, 8; 111, 4; 112, 4;Neh 9, 17.31; 2 Cro $30,9$.

6. La incapacidad para la misericordia y la imposibilidad de la intercesión muestran la inflexibilidad que revela en el creyente la percepción de la vida de fe como un deber penoso. Para perdonar hay que haber renunciado a toda venganza y es preciso estar plenamente reconciliados con la propia historia, en una experiencia gozosa de relación con el Señor. Jonás presenta rasgos que lo asemejan mucho al hermano mayor de la parábola de Lc 15 , aquel que no puede aceptar la fiesta por el retorno de un hermano que ha gozado la vida mientras que él permanecía en la casa del padre pero viviendo como un esclavo.

7. Una figura que contrasta fuertemente con la del profeta Oseas, que para conducir al pueblo a la conversión y a la salvación, se mete dentro de la realidad de pecado casándose precisamente con una «prostituta» por su condición de pertenencia al pueblo que se está prostituyendo en la idolatría. 
tima por un ricino por el que nada ha hecho y no le pertenece, cuánto más, entonces, por una ciudad llena de hombres incapaces de distinguir entre su derecha y su izquierda (como los niños o los ancianos, sin responsabilidad, por tanto, que es lo que en realidad nos pasa a todos ante nuestro pecado cuando finalmente caemos en la cuenta de él).

Hay que subrayar que en el discurso de Dios no se menciona la conversión de los ninivitas. La salvación tiene una dimensión fundamental de gratuidad que ahora aparece. El amor de Dios nos hace a todos niños y muestra nuestra pequeñez. La penitencia responde a esto, revela un perdón ya dado que necesita la confesión para hacerse operativo, pero que no es causado por la confesión. Más bien, esta es posible gracias al perdón de Dios. Nínive, con sus actos de penitencia, muestra haber sido incapaz de distinguir su derecha de su izquierda. Y esto ha sido una gracia otorgada por la mediación del profeta.

El libro termina con la pregunta que Dios plantea a Jonás: ¿Es justo conmoverse por la ciudad y perdonarla? Y nosotros, a quienes se dirige la $\mathrm{Pa}$ labra del Señor, ¿aceptamos un Dios que lleva la misericordia a tales extremos? En última instancia, ¿aceptamos a un Dios que al morir nos revela «que no sabemos lo que hacemos»? (Lc 23, 34).

La pregunta del libro queda abierta, sin respuesta. Es el lector quien debe tomar postura. El que es llamado al sacerdocio, ¿quiere ser mediador de esa misericordia acogiendo la vocación que Dios? Es una pregunta crucial, pero para responderla es preciso mirar a su cumplimiento en el Señor Jesús, nuestro tercer y último punto.

\section{EL CUMPLIMIENTO NEOTESTAMENTARIO}

Lo que fue revelado en el texto fundante del Éxodo y todo lo que se concreta en el envío de los profetas halla su cumplimiento en el Señor Jesús que llama a los Doce.

En el evangelio de Mateo, a este hecho lo precede una alusión a la conmoción que siente Jesús ante la multitud. Se lee en él: «Al ver a la multitud [Jesús] sintió compasión de ellos porque estaban cansados y abatidos como ovejas sin pastor. Entonces dijo a sus discípulos: 'La mies es abundante, pero los obreros son pocos. Rogad por tanto al dueño de la mies que envíe obreros a su mies'» (Mt 9, 36-38). Y continúa: «Jesús llamó a sus doce discípulos y les dio poder para expulsar espíritus inmundos y para curar toda clase de enfermedades y dolencias» (Mt 10,1).

También aquí todo nace de la misericordia. Jesús, «el rostro de la misericordia del Padre» (Misericordiae vultus, 1), viendo al pueblo abandonado a su suerte, como ovejas sin pastor, se conmueve y llena de compasión. El verbo usado (splagnizomai) expresa precisamente ese sentimiento visceral de quien está movido a piedad y decide intervenir y ayudar. Jesús, «el Buen 
Pastor», ve las necesidades de su grey y pide obreros, o mejor, pide que se rece, que se pidan pastores según el corazón de Dios, signos de la misericordia del Padre. La vocación sacerdotal es un don.

Jesús llama así a los doce discípulos y los instruye sobre su misión: predicar el reino, curar a los enfermos, resucitar muertos, expulsar demonios, sin dinero, ni alforjas, ni dos túnicas, ni sandalias, ni bastón, llevando el don de la paz (Mt 10, 5-15). La llamada es para el envío y para cumplir las obras del Maestro, al servicio del reino en gratuidad absoluta, con la conciencia de ser mandados, portadores y donadores de algo que no les pertenece. Esto es lo que quiere decir ser obreros para la mies, y es tarea encomendada a los apóstoles y a aquellos que prolongan su misión.

Toda vocación es siempre para la misión y mucho más la vocación sacerdotal. Como Moisés, llamado para liberar al pueblo, como los profetas, enviados para la conversión. Los discípulos, llamados por Jesús, son separados, dejan las redes, y lo siguen, pero para volver hacia los hermanos y ser para ellos mediadores misericordiosos del don de la salvación.

Anunciando el reino, sobre todo: «ld anunciando que está llegando el reino de los cielos (Mt 10,7). En la misión lo prioritario es la palabra, el anuncio. Sin esto los mismos signos resultan incomprensibles, o al menos sometidos a interpretaciones ambiguas. Ante los milagros de Jesús se puede decir que es un mago, un curandero o incluso que «expulsa los demonios por arte de Belzebú» (Mt 12, 24). Sin embargo, son signos que anuncian la venida del reino, signos de salvación, de perdón y de vida. Palabra y signo son complementarios, explican recíprocamente el don de Dios.

$Y$ ahí aparece el gesto profético de victoria: Jesús confiere a los suyos un poder, el de hacer misericordia, curar, vencer a la muerte, expulsar los demonios. Son gestos que hacen visible la redención, que preanuncia la pascua con su victoria definitiva sobre el pecado, sobre todo aquello que aprisiona y domina a los hombres quitándoles su libertad, su vida, su gozo.

Los medios que han de usar son también adecuados a la misión recibida: sencillez, pobreza, confianza absoluta en Dios; ni oro ni plata, ni dos túnicas, ni sandalias ni bastón ${ }^{8}$. Los discípulos deben dar testimonio del «absoluto de Dios» con una vida sencilla y sin seguridades humanas, conscientes de la absoluta importancia de la proclamación del reino, hasta el punto de renunciar a cualquier preocupación por la vida para confiarse al Dios de la vida.

Porque todo viene únicamente de Dios, y gratis. Y por eso aquellos que han sido llamados por el Señor, no por sus méritos, sino por gracia, no por sus

8. Mateo pone mucho énfasis en el hecho de no llevar provisión alguna para el viaje. Por eso los discípulos no deberían tener dos túnicas, signo de seguridad y tranquilidad para el futuro; ni oro ni plata, medios para vivir sin preocupaciones y que proporcionan el respeto y la consideración de los otros. 
cualidades o capacidades, sino únicamente por la libre elección del Señor ${ }^{9}$, lo devuelven gratis (Mt 10,8). La vocación es siempre gratuita, es un don inmerecido.

Además, por regla general los elegidos son los pequeños, para que se vea bien la inadecuación radical del hombre al que se le encomienda el proyecto divino ${ }^{10}$. La experiencia de la pequeñez y de la inadecuación es constitutiva en la aventura vocacional de todos, y muy particularmente en la sacerdotal, porque el asumir en la propia historia la llamada de Dios es descubrimiento y aceptación de un proyecto que no nos pertenece. Es acogida de un don gratuito, y por eso insondable.

Se va a Dios porque Él es el que llama, y los motivos y criterios de la llamada están ocultos en su libre querer. No es el hombre quien decide autónomamente el seguimiento y después el cumplimiento de la misión. Es necesario que sea Dios quien llame y envíe, «dando el poder», como dice Mateo.

El servicio a los hermanos se recibe como don que hay que cumplir. $Y$ por ser recibido gratuitamente, sin méritos y sin poder dar nada a cambio, es ofrecido también gratuitamente a aquellos a quienes se es enviado ${ }^{11}$. Pues todo en Dios es gratuito: la elección, el envío, el perdón, el sol y la lluvia sobre justos e injustos (contradiciendo de esta manera nuestra idea de justicia), el alimento para los pájaros y la belleza de las flores de los campos (revelándose de esta forma como padre amoroso y providente). Al responder a la vocación sacerdotal, uno se convierte en testigo y mediador de todo ello.

Es este el don que es confiado a los Doce. Y la lista de los Doce es significativa: primero, Simón, llamado Pedro, y su hermano Andrés; luego, Santiago, el hijo de Zebedeo, y su hermano Juan; Felipe y Bartolomé; Tomás y Mateo, el publicano; Santiago, el hijo de Alfeo, y Tadeo; Simón el cananeo y Judas Iscariote, el que lo entregó (Mt 10, 2-4).

El grupo es heterogéneo. La llamada de Jesús no está condicionada por las diferentes pertenencias sociales y culturales. Entre los Doce está Pedro, indicado por su propio nombre y señalado como «primero», hay hermanos,

9. Mateo no habla explícitamente de selección, de elección, pero está implícita. Lucas explicita: «Reunió a sus discípulos, eligió de entre ellos a doce» (Lc 6, 12); también Marcos: "Llamó a los que él quiso» (Mc 3, 13).

10. Es siempre así en las cosas de Dios. Piénsese en Abel (el primogénito, el «soplo»), en David (tan pequeño e insignificante que ni siquiera es invitado para el sacrificio de Samuel), en Jeremías (un joven que no tiene autoridad para hablar), en las mujeres (Débora, Judit, Ester), y en los «pequeños» de los «evangelios de la infancia» que Lucas pone alrededor de Jesús: Isabel y Zacarías (ancianos, estériles, como Abrahán y Sara), María (que era virgen), los pastores (sin relevancia social), Simeón y Ana (los «pobres de Yahvé» que esperaban la consolación de Israel).

11. La gratuidad no es sólo una condición exterior, sino un componente intrínseco del anuncio, única posibilidad de transmitir lo que se ha recibido gratuitamente de Dios. Por ello, esa exigencia de no llevar oro ni plata no es sólo una invitación a la pobreza, sino sobre todo un modo de señalar la calidad del anuncio. 
hay pescadores, pero también un publicano, recaudador de impuestos y colaborador de los ocupantes ${ }^{12}$; hay además un zelota, un revolucionario, Simón el cananeo ${ }^{13}$. Y parece que también Judas podría pertenecer a ese grupo.

Precisamente esa mención de Judas «Iscariote, el que lo entregó», puesta al final, como enfatizando su presencia, da que pensar. El proyecto divino es la oferta de la salvación, pero entre quienes son llamados a realizarlo ha anidado el mal. Y Jesús parece aceptarlo, parece haberlo tenido en cuenta, pero para reabsorberlo en un amor más grande.

Cuando Dios elige llamar a hombres a colaborar en su designio de redención elige también comprometerse radicalmente con la realidad, aceptando incluso correr el riesgo de la traición. Es el misterio hermoso y terrible a la vez de la libertad humana que marca la historia del mundo, una historia que la misericordia del Señor quiere transformar en historia de salvación.

Porque Dios es más grande que el mal y lo afronta para vencerlo a lo largo de la aventura humana hasta su cumplimiento en el Señor Jesús, a cuyo seguimiento son llamados los Doce; y precisamente estos Doce, entre los cuales está Judas, que lo traiciona, y Pedro, que lo niega tres veces, y Santiago y Juan, que en Getsemaní duermen mientras su Maestro está en agonía, y todos los demás, que lo abandonan y dejan solo en el momento de su muerte. Y es justamente ahí donde se revela plenamente la misericordia de Dios.

La mención de Judas entre los Doce y la manifestación de la fragilidad de los otros se convierten, pues, en un elemento trágico, pero a la vez esperanzador. Porque revelan la resistencia del hombre al proyecto de salvación de Dios, pero a la vez testimonian que en ese proyecto ha sido englobado ya el pecado del hombre, englobado y perdonado y vencido.

Esta es la realidad de gracia para cuya proclamación ha sido mandado el sacerdote; esta es la buena noticia que tiene que anunciar y que puede cambiar el mundo: el mal ha sido derrotado, la misericordia de Dios, de la que brota la vocación al servicio del reino, lo ha invadido todo.

12. No se excluye que esto ofreciera la oportunidad de enriquecerse aprovechándose de la posición personal; quizá pueda verse también desde esa perspectiva la figura de Zaqueo (Lc 19, 1-10).

13. El apelativo probablemente quiere indicar alguien perteneciente a la resistencia antirromana, pues podría venir del hebreo qn', «celo»; cf. a este respecto Lc 6, 15 y Hch 1, 13, que emplean «zelota». 